\title{
Comparison of energy-related isoenzymes between production and racing Arabian camels
}

\author{
Mohammed S. AL-Harbi ${ }^{1}$, Sayed A. M. Amer ${ }^{1,2^{*}}$ \\ ${ }^{1}$ Department of Biology, Faculty of Science, Taif University, Taif, Saudi Arabia \\ ${ }^{2}$ Department of Zoology, Faculty of Science, Cairo University, Cairo, Egypt \\ Email: *yasser92us@yahoo.com
}

Received 14 September 2012; revised 21 October 2012; accepted 25 November 2012

\begin{abstract}
Native polyacrylamide gel electrophoresis have been applied for the analyses of alkaline phosphatase (ALP), malate dehydrogenase (Mdh) and malic (ME) isoenzymes in Arabian camel for racing and production. Two fractions for each of these isoenzymes have been recorded in the studied breeds. $A L P$ showed very weak patterns without remarkable difference between the two breeds and this is an indication to that the samples used were healthy and being from the same age. The cytosolic $M d h-1$ and $M E-1$ have been recorded in both camel breeds with high intensity. The mitochondrial $M d h-2$ and $M E-2$ have been recorded with small intensity in production breeds commonly. The present data indicate the necessity of the mitochondrial $M d h-2$ for energy production in racing breed and the responsibility of the cytosolic Mdh-1 for lipogenesis and energy production in both breeds. We therefore may assume that the appearance of both Mdh forms is necessary for both energy and lipid production in the production breeds while Mdh-1 was useful as bioenergetic enzyme necessary for racing. The different expressions are indications of the difference in the physiological adaptations of both camel breeds and are not for a systematic value.
\end{abstract}

Keywords: Malate Dehydrogenase; Malic Enzyme; Racing Camel; Production Camel; Electrophoresis

\section{INTRODUCTION}

The distribution of the Arabian camel extends in arid zones, from northwestern India and the lowlands of Afghanistan to the extremity of the Arabian Peninsula and Somalia to the south and westward across the African deserts [1,2]. The physiological characteristics of the dromedary are well known to be adapted to fit with such arid conditions. Of these adaptations are its wide range

${ }^{*}$ Corresponding author. of body temperature, its water metabolism and its ability to travel over long distances with less effort [3]. It is expected to find differences in the physiological data of energy related enzymes between production and racing camels. So far there is no physiological study comparing both production and racing camel breeds.

Many communities throughout the world are depending on camels in the utilization of their meat, milk, leather and wool. Camel also can be used as an important sport and tourism resource, particularly, in the Arabian Gulf countries [4-7].

Malate dehydrogenase is considered as one of the most extensively studied isozyme systems [8]. This enzyme with lactate dehydrogenase, are very suitable systems for studying several metabolic, genetic, ecological features, and they are very useful in systematic studies [9-12]. $\mathrm{MDH}$ is a homodimeric enzyme and it is well known for the many cell compartment-specific isoenzymes that have been characterized from various organisms $[13,14]$. There is a mitochondrial MDH that functions in the tricarboxylic acid cycle which is usually NAD + -dependent. Most eukaryotes that have been studied also have a cytosolic MDH isoform. The cytosolic $\mathrm{MDH}$, also known as NADP-malic enzyme $(M E)$, catalyze the NADP dependent oxidative decarboxylation of malate into pyruvate and carbon dioxide to generate NADPH. $M E$ is thought to be a key enzyme in lipid biosynthesis. Eukaryotic $M E$ is found in both vertebrates and invertebrates as well as in plants [15]. Among other functions, these compartment-specific isoforms help to shuttle reducing equivalents in the form of malate/oxalacetate across membranes and into various cell compartments where they are needed [16].

Electrophoretic investigation of two enzymes (Mdh and $M E$ ) of the tricarboxylic acid cycle and alkaline phosphatase $(A L P)$ has been conducted for the production and race camel breeds inhabiting Saudi Arabia. This investigation aimed to compare whether these enzymes differ between the studied breeds. 


\section{MATERIALS AND METHODS}

\subsection{Sample Preparation and Isoenzyme Assay}

Blood samples from 7 individuals from production breed and 5 individuals from racing breeds (all aging $2-3$ years old) were freshly obtained from a private farm in Taif city, placed in tubes with an anticoagulant and immediately stored at $4^{\circ} \mathrm{C}$ overnight. The specimens were then centrifuged at $3000 \mathrm{rpm}$ for approximately $3-5$ minutes. The plasmatic supernatants were stored at $-80^{\circ} \mathrm{C}$ for further isoenzyme assay.

For electrophoresis, $30 \mu \mathrm{L}$ of the plasma was mixed with $10 \mu \mathrm{L}$ of treatment buffer and $35 \mu \mathrm{L}$ of this mixture was loaded in the well. Isoenzymes were electrophorased in $10 \%$ native-polyacrylamide gel as described by Stegemann et al. [17]. After electrophoresis, the gels were stained according to their enzyme system with the appropriate substrate and chemical solutions then incubated at room temperature in dark for complete staining. In most cases, the incubation for about 1 to 2 hours is enough.

\subsection{Alkaline Phosphatase (ALP)}

After electrophoresis, the gel was soaked in $100 \mathrm{ml}$ of 50 $\mathrm{mM}$ Na-acetate buffer pH 5.0 containing $100 \mathrm{mg}$ Fast blue BB salt, $100 \mathrm{mg} \alpha$-naphthyl phosphate, $100 \mathrm{mg}$ $\mathrm{MgCl}_{2} 100 \mathrm{mg} \mathrm{MnCl}_{2}$ and $1 \mathrm{~g} \mathrm{NaCl}$ in $100 \mathrm{ml}$ of $0.1 \mathrm{M}$ Tris $\mathrm{HCl} \mathrm{pH} 8.5$ [18].

\subsection{Malate Dehydrogenase (Mdh)}

After electrophoresis, the gel was soaked in $100 \mathrm{ml}$ of $0.05 \mathrm{M}$ Tris $\mathrm{HCl} \mathrm{pH} 8.5$ containing $25 \mathrm{mg} \mathrm{NBT}, 25 \mathrm{mg}$ EDTA, $25 \mathrm{mg}$ NAD, $10 \mathrm{mg}$ malic acid and $3 \mathrm{mg}$ PMS [19]. $0.05 \mathrm{M}$ Tris $\mathrm{HCl} \mathrm{pH} 8.5$ was prepared by dissolving $0.605 \mathrm{~g}$ Tris in $50 \mathrm{ml}$ distilled water. The $\mathrm{pH}$ was adjusted to 8.5 by $\mathrm{HCl}$. Then the solution was completed to $100 \mathrm{ml}$ with distilled water.

\subsection{Malic Enzyme (ME)}

After electrophoresis, the gel was soaked in $100 \mathrm{ml}$ of $0.05 \mathrm{M}$ Tris $\mathrm{HCl} \mathrm{pH} 8.5$ containing $25 \mathrm{mg}$ NBT, $25 \mathrm{mg}$ EDTA, $25 \mathrm{mg}$ NADP, $10 \mathrm{mg}$ malic acid, $100 \mathrm{MgCl}_{2}$ and PMS [19].

\subsection{Gel Fixation}

After the appearance of the enzyme bands, the reaction was stopped by washing the gel two or three times with tap water. This was followed by adding the fixative solution, which consists of ethanol and $20 \%$ glacial acetic acid $(9: 11 \mathrm{v} / \mathrm{v})$. The gel was kept in the fixative solution for 24 hours and then was photographed.

\subsection{Statistics}

All gels were scanned using Gel Doc-2001 Bio-Rad system. For isoenzymes, the bands of enzyme activity were designated using the known system of nomenclature [20]. An abbreviation which corresponds to the name of the enzyme designated each locus. When multiple loci were involved, the fastest anodal protein band was designated as locus one, the next as locus two and so on. Student t-test in the SPSS package v. 13 was used to calculate the significant differences of the percentage amounts for isoforms among the different studied tissues.

\section{RESULTS AND DISCUSSION}

Table 1 showed the mean and SE values for the total and fractional enzyme percentage amounts of the studied isoenzymes. The data indicated that there was no significant variation between racing and production camel breeds in all analyzed isoenzymes. Electrophoresis of alkaline phosphatase $(A L P)$ isoenzyme showed very weak monomorphic fractions in the studied samples of both camel breeds (Figure 1). The fastest anodal fraction $(A L P-1)$ was faint and broad while the second isoform $(A L P-2)$ was very sharp and close to the origin of the gel. There was no remarkable difference in the pattern of this enzyme for both breeds. As abnormal alakaline phosphatase is an indicator for liver or bone abnormalities $[21,22]$, the present results may indicate that the studied samples are healthy. On the other hand, since the activity of this enzyme differs by aging [23-26], the insignificance in the enzyme activity between the studied breeds may be attributed to that the selected camel samples are from the same age.

Malate dehydrogenase $(M d h)$ isoenzyme has recorded two monomeric isoforms: the cytosolic Mdh-1 showing faster mobility with high intensity in the gel (Figure 2) and the mitochondrial Mdh-2 acquiring sharp density at the top of the gel. Mdh-1 was recorded in all production and race samples while $M d h-2$ was recorded commonly in the production breed (see the recoded phenotypes in Figure 2).

Table 1. Mean \pm SE of the percentage amount for the studied isoenzymes in plasma of production and racing Arabian Camel.

\begin{tabular}{cccc}
\hline Enzyme & Fraction & Production & Racing \\
\hline \multirow{3}{*}{$\boldsymbol{M d h}$} & $\mathbf{1}$ & $14.09 \pm 1.69$ & $11.26 \pm 1.69$ \\
& $\mathbf{2}$ & $6.39 \pm 0.22$ & $5.79 \pm 0.00$ \\
& Total & $20.47 \pm 1.65$ & $12.42 \pm 2.84$ \\
$\boldsymbol{M E}$ & $\mathbf{1}$ & $11.91 \pm 1.65$ & $11.78 \pm 1.45$ \\
& $\mathbf{2}$ & $6.29 \pm 0.61$ & $4.97 \pm 0.00$ \\
& Total & $16.39 \pm 1.38$ & $13.43 \pm 2.82$ \\
$\mathbf{A L P}$ & $\mathbf{1}$ & $18.01 \pm 1.94$ & $17.19 \pm 3.36$ \\
& $\mathbf{2}$ & $11.68 \pm 0.90$ & $11.87 \pm 0.57$ \\
& Total & $32.63 \pm 3.23$ & $28.97 \pm 3.43$ \\
\hline
\end{tabular}




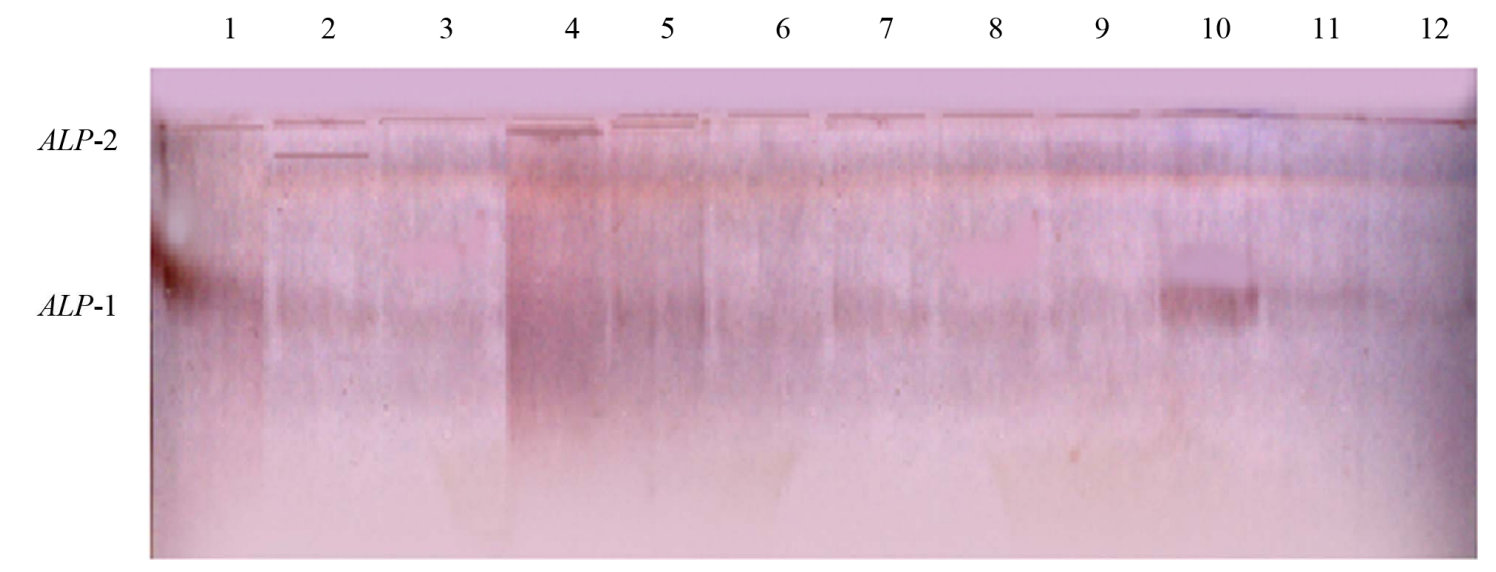

\begin{tabular}{cccccccccccccc}
\hline RF & Lane1 & Lane2 & Lane3 & Lane4 & Lane5 & Lane6 & Lane7 & Lane8 & Lane9 & Lane10 & Lane11 & Lane12 \\
\hline 0.009 & + & + & + & + & + & + & + & + & + & & + & + & + \\
0.246 & + & + & + & + & + & + & + & + & + & & + & + & + \\
\hline
\end{tabular}

Figure 1. Electrophoretic banding pattern (above) and the recorded phenotypes with relative mobility (RF) (below) of the $A L P$ isoenzyme in production $(1-7)$ and racing $(8-12)$ Arabian camel.

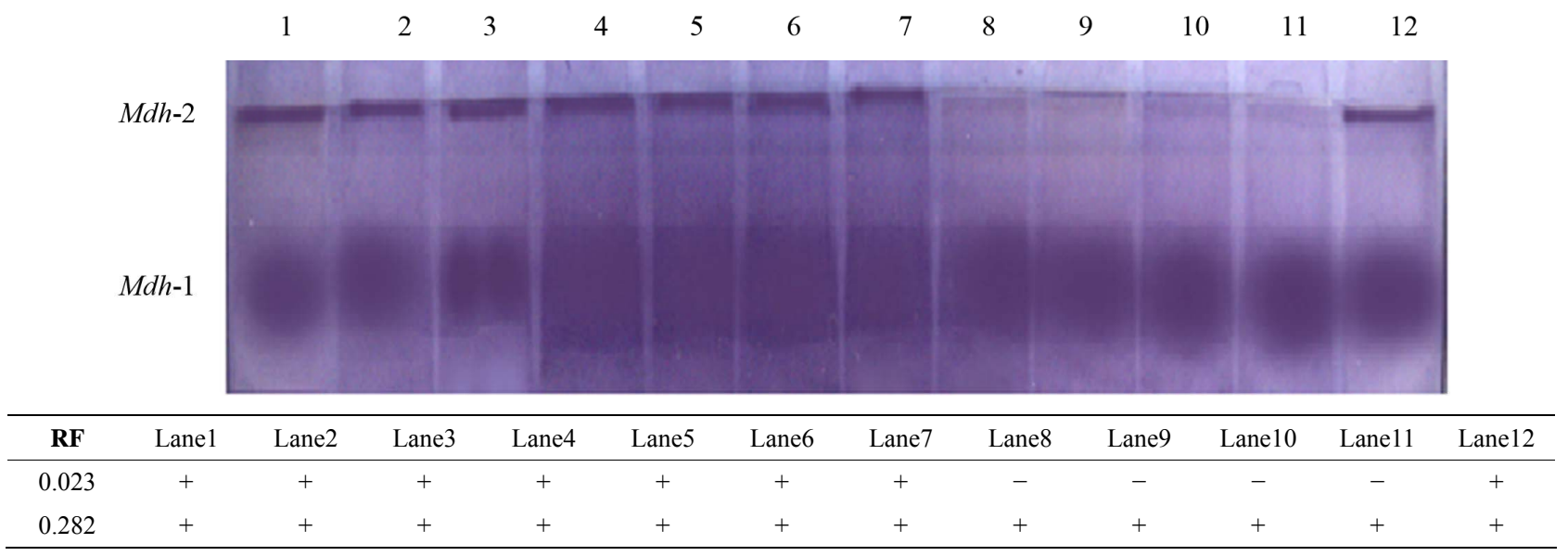

Figure 2. Electrophoretic banding pattern (above) and the recorded phenotypes with relative mobility (RF) (below) of the Mdh isoenzyme in production (1 - 7) and racing ( 8 - 12) Arabian camel.

Malic enzyme $(M E)$ showed two isoforms with the frist $(M E-1)$ being common and highly active in the two studied breeds. The second isoform (ME-2) was located near the top of the gel and was common in the production samples and nearly absent in the race breed (Figure 3).

The present results revealed that the cytosolic (Mdh-1 and $M E-1)$ were the only expressed isoenzymes in most samples of racing camel while both cytosolic and mitochondrial isoforms were expressed in production breed. The two essential malate dehydrogenases, $M d h-1$ (cytosolic malate dehydrogenase) and Mdh-2 (mitochondrial malate dehydrogenase), play important roles in the Krebs cycle for energy production through aerobic respiration [27]. $M d h-1$ and $M d h-2$ are also involved in lipid synthesis by providing extramitochondrial reducing equivalents from the oxidation of malate $[28,29]$.
$M E-1$ (malic enzyme), an NADP-dependent lipogenic enzyme, is involved in the conversion of L-malate to pyruvate. $M E-1$ is part of a shuttle that transfers acetyl groups from the mitochondria to the cytosol, forming a link between the glycolytic pathway and the citric acid cycle [30]. ME-1 promotes the release of acetyl-coezyme A and NADPH from the mitochondria into the cytosol for fatty acid biosynthesis. Furthermore, the cytosolic Mdh (L-malate: NADP+ oxaloacetate-decarboxylating oxidoreductase), also known as NADP-malic enzymes $(M E)$ [15], catalyze the NADPdependent oxidative decarboxylation of malate into pyruvate and carbon dioxide to generate NADPH. Due to its ability to produce NADPH, $M E$ is thought to be a key enzyme in lipid biosynthesis.

Wurochekke et al. [31] expected that intermediate of the TCA cycle inhibits mitochondrial malate dehydro- 


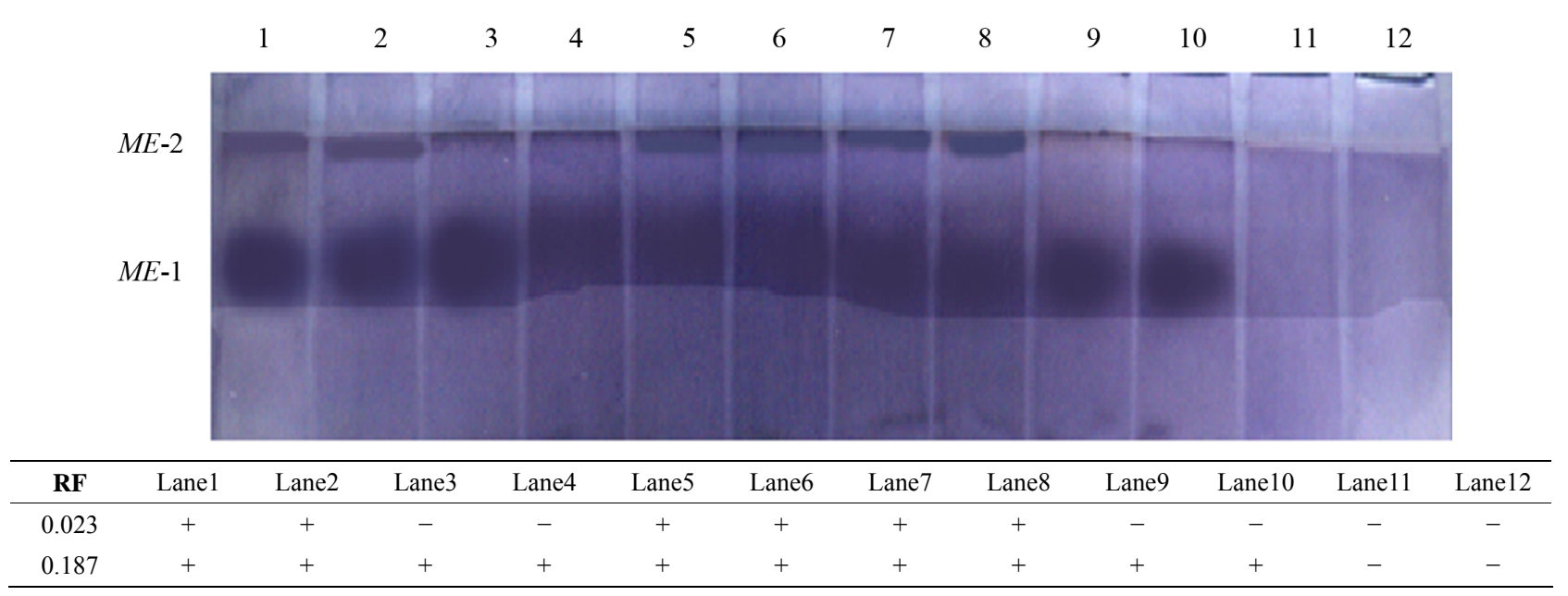

Figure 3. Electrophoretic banding pattern (above) and the recorded phenotypes with relative mobility (RF) (below) of the $M E$ isoenzyme in production ( 1 - 7) and racing ( 8 - 12) Arabian camel.

genase (Mdh-2). Aspartate which can readily cross the inner mitochondrial membrane is formed from oxaloacetate by transamination and it has significantly inhibited the activity of the enzyme. $M d h-1$ as a cytosolic malate dehydrogenase catalyses the reduction of oxaloacetate to malate in the cytosol. As the racing camel consumes more energy during racing, this could accelerate the TCA cycle and increase the production of the intermediate metabolites which could be expected to reduce the activity of Mdh-2. This may be the reason why the second isoform has not been expressed in racing camel. Because the production camel has been adapted to use both energy and lipids, the two isoforms of these energetic and lipogenic enzymes have been clearly expressed. We therefore may assume that the appearance of both Mdh forms is necessary for both energy and lipid production in the production breeds while $M d h-1$ was useful as bioenergtic enzyme necessary for racing.

\section{CONCLUSION}

MDH and ME isoenzymes showed different expressions in the plasma of the production and racing Arabian camels. These different expressions are indications of the difference in the physiological adaptations of both camel breeds and are not for a systematic value.

\section{ACKNOWLEDGEMENTS}

We are grateful to Dr. Shawkat Ahmed at Ain Shams University of Egypt for his technical support in conducting the practical part of this work.

\section{REFERENCES}

[1] Sweet, L.E. (1965) Camel pastoralism in North Arabia and minimal camping unit. In: Leeds, A. and Vayda, A.P.,
Eds., Culture and Animals, American Association for the Advancement of Science, Washington DC, 129-152.

[2] Mahmoud, A.H., Alshaikh, M.A., Aljumaah, R.S. and Mohammed, O.B. (2012) Genetic variability of camel (Camelus dromedarius) populations in Saudi Arabia based on microsatellites analysis. African Journal of Biotechnology, 11, 11173-11180.

[3] Bourzat, D. and Wilson, R.T. (1987) Research on the dromedary in Africa. Scientific and Technical Review, 6, 383-389.

[4] Wilson, R.T. (1984) The camel. Longman Group Ltd., Essex.

[5] Abdurahman, O.A.S. and Bornstein, S. (1991) Diseases of camels (Camelus dromedarius) in Somalia and prospects for better health. Nomadic Peoples, 29, 104-112.

[6] Kohler-Rollefson, I. (1992) The Raika dromedary breeders of Rajasthan: A pastoral system in crisis. Nomadic Peoples, 30, 74-83.

[7] Snow, D.H., Billah, A.M., Ridha, A. and Frigg, M. (1992) Plasma concentrations of some vitamins in camels. Proceeding of First International Camel Conference, Dubai, 2-6 February 1992, pp. 335-338.

[8] Laganà, G., bellocco, E., mannucci, C., leuzzi, U., Tellone, E., Kotyk1, A. and Galtieri, A. (2006) Enzymatic urea adaptation: Lactate and malate dehydrogenase in elasmobranchs. Physiological Research, 55, 675-688.

[9] Almeida-Val, V.M.F., Schwantes, M.L. and Val, A.L. (1990) LDH isozymes in Amazon fish. I. Electrophoretic studies on two species from Serrasalmidae family: $M y$ lossoma duriventris and Colossoma macropomum. Comparative Biochemistry and Physiology B, 95, 77-84.

[10] Almeida-Val, V.M.F., Schwantes, M.L. and Val, A.L. (1991) LDH isozymes in Amazon fish. II. Temperature and $\mathrm{pH}$ effects in LDH kinetic properties from Mylossoma duriventris and Colossoma macropomum (Serrasalmidae). Comparative Biochemistry and Physiology B, 98, 79-86.

[11] Almeida-Val, V.M.F., Paula-Silva, M.N., Caraciolo, M.C. M., Mesquita, L.S.B., Farias, I.P. and Val, A.L. (1992) 
LDH isozymes in Amazon fish. III. Distribution patterns and functional properties in Serrasalmidae (Teleostei: Ostariophysi). Comparative Biochemistry and Physiology $B$, 103, 119-125. doi:10.1016/0305-0491(92)90422-N

[12] Coppes, Z.L. (1990) Divergence of duplicate genes in three Scianid species (Perciformes) from the South coast of Uruguay. Comparative Biochemistry and Physiology B, 96, 33-39. doi:10.1016/0305-0491(90)90337-S

[13] Gietl, C. (1992) Malate dehydrogenase isoenzymes: Cellular locations and role in the flow of metabolites between the cytoplasm and cell organelles. Biochimica et Biophysica Acta, 1100, 217-234. doi:10.1016/0167-4838(92)90476-T

[14] Goward, C.R. and Nicholls, D.J. (1994) Malate dehydrogenase: A model for structure, evolution, and catalysis. Protein Science, 3, 1883-1888. doi: $10.1002 /$ pro. 5560031027

[15] Daniš, P. and Farkas, R. (2009) Hormone-dependant and hormone-independant control of metabolic and developmental functionals of malate dehydrogenase. Endocrine Regulations, 43, 39-52.

[16] Schnarrenberger, C. and Martin, W. (2002) Evolution of the enzymes of the citri acid cycle and the glyoxylate cycle of higher plants. European Journal of Biochemistry, 269, 868-883. doi:10.1046/j.0014-2956.2001.02722.x

[17] Stegemann, H., Afify, A.M.R. and Hussein, K.R.F. (1985) Cultivar identification of dates (Phoenix dactylifera) by protein patterns. Second International Symposium of Biochemical Approaches to Identification of Cultivars, Braunschweing, 44.

[18] Wendel, J.F. and Weeden, N.F. (1989) Visualization and interpretation of plant isozymes. In: Soltis, D.E. and Soltis, P.S., Eds., Isozymes in Plant Biology, Dioscorides Press, Portland, 5-45. doi:10.1007/978-94-009-1840-5_2

[19] Jonathan, F.W. and Wendell, N.F. (1990) Visualization and Interpretation of plant isozymes. In: Soltis, D.E. and Soltis, P.S., Eds., Isozymes in Plant Biology, Champan and Hall, London, 5-45.

[20] Allendorff, W. and Utter, F.M. (1978) Population genetics. In: Hoaran, W.S. and Randalal, D.J., Eds., Fish Physiology, Academic Press, New York, 407-454.

[21] Hirano, K., Domar, U.M., Yamamoto, H., BrehmerAndersson, E.E., Wahren, B.E. and Stigbrand, T.I. (1987) Levels of alkaline phosphatase isozymes in human semi- noma. Cancer Research, 47, 2543-2546.

[22] Yorio, M.A., Sembaj, A., Sanz, E., Carriazo, C. and Barral, J.M. (2000) Alkaline phosphatase isoenzymes for the diagnosis of metastatic tumors and lymphomas of liver and bone. MEDICINA (Buenos Aires), 60, 311-315.

[23] Eastman, J.R. and Blxler, D. (1977) Serum alkaline phosphatase: Normal values by sex and age. Clinical Chemistry, 23, 1769-1770.

[24] Sekine, J., Moria, Z., Oura, R. and Asahida, Y. (1988) A consideration on factors affecting water consumption of growing calves. Japan Society of Zootechnical Science, Annual Meeting Abstracts, 49.

[25] Watanabe, F., Miyazaki, T. Takeuchi, T., Fukaya, M. and Nomura, T. (2008) Effects of FAK ablation on cerebellar foliation, Bergmann glia positioning and climbing fiber territory on Purkinje cells. European Journal of Neuroscince, 27, 836-854.

[26] Kellett, K.A.B., Williams, J., Vardy, E.R.L.C., Smith, A.D. and Hooper, N.M. (2011) Plasma alkaline phosphatase is elevated in Alzheimer's disease and inversely correlates with cognitive function. International Journal of Molecular Epidemiology and Genetics, 2, 114-121.

[27] Zhou, S.L., Li, M.Z., Li, Q.H., Guan, J.Q. and Li, X.W. (2012) Differential expression analysis of porcine MDH1, $\mathrm{MDH} 2$ and ME1 genes in adipose tissues. Genetics and Molecular Research, 11, 1254-1259. doi:10.4238/2012.May.9.4

[28] Schmid, G.M., Converset, V., Walter, N. and Sennitt, M.V. (2004) Effect of high-fat diet on the expression of proteins in muscle, adipose tissues, and liver of C57BL/6 mice. Proteomics, 4, 2270-2282. doi: 10.1002/pmic. 200300810

[29] Bourneuf, E., Herault, F., Chicault, C. and Carre, W. (2006) Microarray analysis of differential gene expression in the liver of lean and fat chickens. Gene, 372, 162-170. doi:10.1016/j.gene.2005.12.028

[30] MacDonald, M.J. (1995) Feasibility of a mitochondrial pyruvate malate shuttle in pancreatic islets. Further implication of cytosolic NADPH in insulin secretion. Journal of Biological Chemistry, 270, 20051-20058.

[31] Wurochekke, A.U., Anthony, A.E. and Obidah, W. (2008) Biochemical effects on the liver and kidney of rats administered aqueous stem bark extract of Xemenia Americana. African Journal of Biotechnology, 7, 2777-2780. 